\title{
Obtaining of Betulin Diacetate and Betulin Dipropionate Composites with Aerosil
}

\author{
Yuriy N. Malyar*a, Svetlana A. Kuznetsova, ${ }^{a, b}$, \\ Tatyana P. Shakhtshneider ${ }^{\mathrm{c}, \mathrm{d}}$ and Mikhail A. Mikhailenko ${ }^{\mathrm{c}}$ \\ ${ }^{a}$ Institute of Chemistry and Chemical Technology SB RAS \\ 50/24 Akademgorodok, Krasnoyarsk, 660036, Russia \\ ${ }^{b}$ Siberian Federal University \\ 79 Svobodny, Krasnoyarsk, 660041, Russia \\ cInstitute of Solid State Chemistry and Mechanochemistry SB RAS \\ 18 Kutateladze Str., Novosibirsk, 630128, Russia \\ ${ }^{d}$ Novosibirsk State University \\ 2 Pirogova Str., Novosibirsk, 630090, Russia
}

Received 26.04.2015, received in revised form 19.05.2015, accepted 31.05.2015

The composites of betulin diacetate and betulin dipropionate with aerosil were obtained by mechanochemical methods. The physico-chemical properties of the composites were studied. The composites are characterized by increased concentration of betulin diacetate and betulin dipropionate at dissolution in water.

Keywords: betulin diacetate, betulin dipropionate, aerosil, mechanochemical activation, mechanocomposites, physico-chemical properties.

DOI: $10.17516 / 1998-2836-2015-8-2-277-286$.

(C) Siberian Federal University. All rights reserved

* Corresponding author E-mail address: yumalyar@gmail.com 


\title{
Получение композитов диацетата
}

\section{и дипропионата бетулина с аэросилом}

\author{
Ю.Н. Маляр ${ }^{a}$, С.А. Кузнецова ${ }^{a, \tilde{\sigma}}$, \\ Т.П. Шахтшнейдер ${ }^{\text {в,г }, \text { М.А. Михайленко }}{ }^{\text {в }}$ \\ ${ }^{a}$ Институт химии и химической технологии СО РАН \\ Россия, 660036, Красноярск, Академгородок, 50/24 \\ ${ }^{6}$ Сибирский федеральный университет \\ Россия, 660041, Красноярск, пр. Свободный, 79 \\ ${ }^{6}$ Институт химии твердого тела и механохимии СО РАН \\ Россия, 630128, Новосибирск, ул. Кутателадзе, 18 \\ 'Новосибирский государственный университет \\ Россия, 630090, Новосибирск, ул. Пирогова, 2
}

Методом механической активации получены композиты диацетата бетулина и дипропионата бетулина с аэросилом и изучены их физико-химические свойства. При растворении композитов в воде достигается повышенная кониентрация диацетата и дипропионата бетулина.

Ключевые слова: диачетат бетулина, дипропионат бетулина, аэросил, механохимическая активация, механокомпозиты, физико-химические свойства.

Диацетат бетулина (3ß, 28-диацетокси-луп-20(29)-ен(1)) (ДАБ) и дипропионат бетулина $(3 \beta, 28$-дипропиокси-луп -20 (29) - ен (1)) (ДПБ) - эфиры уксусной и пропионовой кислот и бетулина - являются перспективными веществами для фармакологии [1-4]. Структурные формулы диацилов бетулина представлены на рис. 1. Одним из основных препятствий, ограничивающих использование этих производных бетулина в медицине и ветеринарии, является их низкая биологическая доступность, связанная с плохой растворимостью в воде.

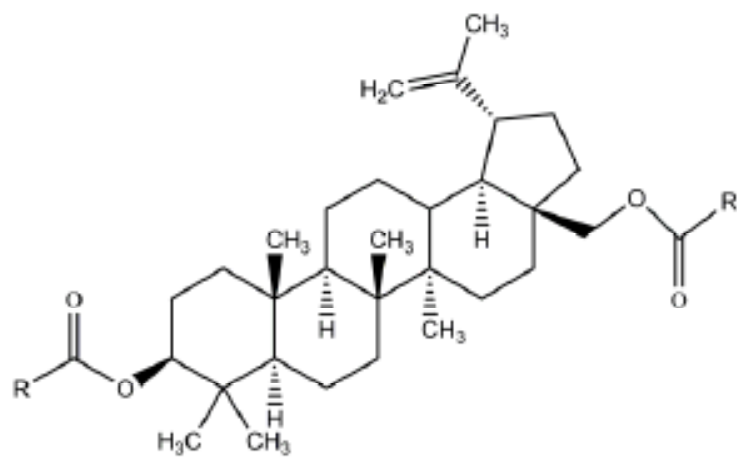

При $\mathrm{R}=-\mathrm{CH}_{3}-$ диацетат бетулина, $\mathrm{R}=-\mathrm{CH} 2-\mathrm{CH} 3$ - дипропионат бетулина

Рис. 1. Структурные формулы диацетата и дипропионата бетулина 


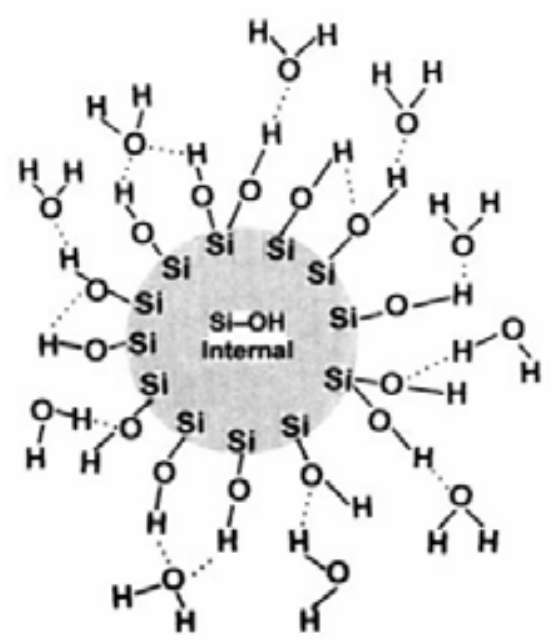

Рис. 2. Структура поверхностного слоя аэросила

Известно, что механическая активация лекарственных веществ приводит к диспергированию и разупорядочению их кристаллической структуры вплоть до полной аморфизации, способствуя увеличению скорости растворения и растворимости субстанций. Добавление при этом полимерного носителя может стабилизировать разупорядоченное состояние лекарственного вещества [5-7]. В качестве носителей можно использовать различные полимеры природного и синтетического происхождения, например поливинилпирролидон, полиэтиленгликоль, арабиногалактан [8-10].

Аморфный непористый диоксид кремния $\left(\mathrm{SiO}_{2}\right)$ с размером частиц от 5 до 40 нм может использоваться в качестве носителя активных веществ в парфюмерии и медицине [11-13]. Адсорбционные свойства аэросила определяются, прежде всего, наличием на его поверхности

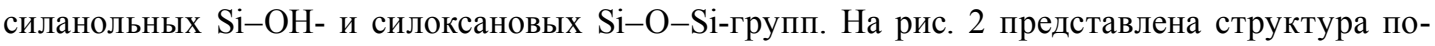
верхностного слоя аэросила.

Целью данной работы являлось получение композитов диацетата и дипропионата бетулина с аэросилом с помощью механической активации, исследование их физико-химических свойств.

\section{Экспериментальная часть}

Диацетат и дипропионат бетулина получали из коры березы по разработанным ранее в ИХХТ СО РАН методикам $[14,15]$, аэросил использовали торговой марки «Полисорб МП».

Механическую активацию (МА) исходных компонентов и смесей ДАБ и ДПБ с аэросилом проводили в ударно-шаровой мельнице SPEX-8000 (США) с массой шаров 60 г и диаметром шаров 0,6 см. Объём стальных барабанов 60 мл, отношение массы навески к массе шаров 1:30, нагрузка на шар $10 \mathrm{~g}$. Соотношение компонентов «диацил бетулина - аэросил» составляло 1:9 (по массе). Продолжительность активации варьировалась от 5 до 30 мин. Для сравнения с механоактивированными образцами были приготовлены физические смеси простым перемешиванием исходных компонентов.

$$
-279-
$$


Растворение образцов проводили в течение 24 ч при $\mathrm{T}=(37 \pm 1){ }^{\circ} \mathrm{C}$ с использованием тестера растворимости 705 DS (Varian Inc, Netherlands). 200 мг смеси помещали в 250 мл воды. Отобранные пробы центрифугировали в течение 15 мин при 8000 об/мин и отфильтровывали с помощью мембранного фильтра (Millipore, $\mathrm{d}=0.2$ мкм). Фильтрат объёмом $\sim 60$ мл выпаривали и растворяли в этиловом спирте. Концентрацию ДПБ в полученном спиртовом растворе определяли на жидкостном хроматографе «Милихром А-02» Эконова», Россия, колонка ProntoSil C18, подвижная фаза - вода-ацетонитрил. В качестве стандарта использовали спиртовые растворы диацилов бетулина. Полученные значения пересчитывали на первоначальный объём фильтрата.

Электронные микрофотографии получены на растровом электронном микроскопе ТМ1000 HITACНI (Япония).

Рентгенофазовый анализ (РФА) проводили на дифрактометре D8 DISCOVER с двухкоординатным детектором GADDS (Bruker), $\mathrm{CuK}_{\alpha}$-излучение.

Инфракрасные спектры нарушенного полного внутреннего отражения (НПВО) в диапа-

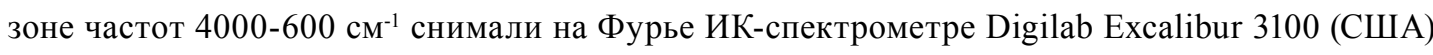
с использованием приставки НПВО фирмы Pike с кристаллом $\mathrm{ZnSe}$ без прессования образцов.

\section{Результаты и обсуждение}

\section{Композиты диацетата бетулина с аэросилом}

Механическая активация смеси диацетата бетулина с аэросилом приводит к гомогенизации смеси в результате диспергирования компонентов и образованию механоактивированных композитов.

На рис. 3 представлены электронные микрофотографии диацетата бетулина, аэросила и смесей диацетата бетулина с аэросилом, механоактивированных в течение 15 и 30 мин.

На рис. 3 видно, что исходный ДАБ представляет собой игольчатые кристаллы с размером частиц от 10 до 100 мкм, аэросил - это белые хлопьевидные агрегаты. Механическая обработка ДАБ с аэросилом в течение 15 мин приводит к тому, что диацетат бетулина теряет кристаллическую форму, смесь становится гомогенной, однородной и состоит из агрегатов частиц размером 5-30 мкм. С увеличением продолжительности механической обработки до 30 мин размер агрегатов увеличивается.

На рис. 4 представлены ИК-спектры физической и механоактивированных смесей ДАБ с аэросилом.

В спектрах механоактивированных смесей диацетата бетулина с аэросилом (кривые 2, 3, 4) наблюдается увеличение интенсивности полос колебаний карбонильной группы в области 1740-1700 см ${ }^{-1}$ по сравнению со спектром физической смеси компонентов (кривая 1). Увеличение интенсивности пиков карбонильной группы при механической активации смесей может быть связано с особенностями метода НПВО, где значительную роль играет поверхность вещества. В случае физической смеси на поверхности образца присутствует в основном аэросил, в то время как при механической обработке происходит увеличение поверхности ДАБ в результате его измельчения и распределения по поверхности аэросила. Кроме того, при механической активации происходит смещение полос колебаний $\mathrm{C}=\mathrm{O}$-группы в область более низких частот, 

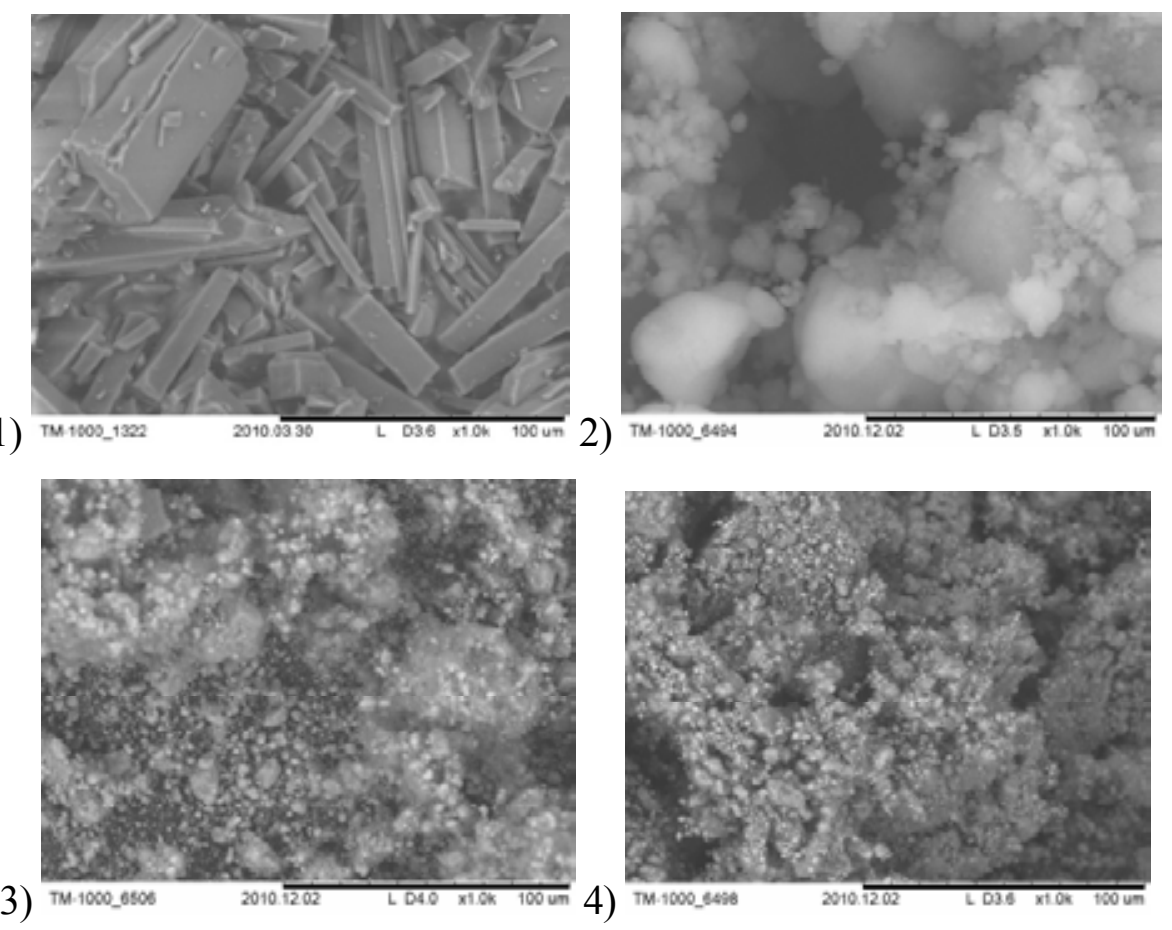

Рис. 3. Электронные микрофотографии (увеличение в 1000 раз): 1 - ДАБ; 2 - аэросила; 3 - смеси ДАБ-аэросил, механически ативированной в течение 15 мин; 4 - смеси ДАБ-аэросил, механически активированной в течение 30 мин

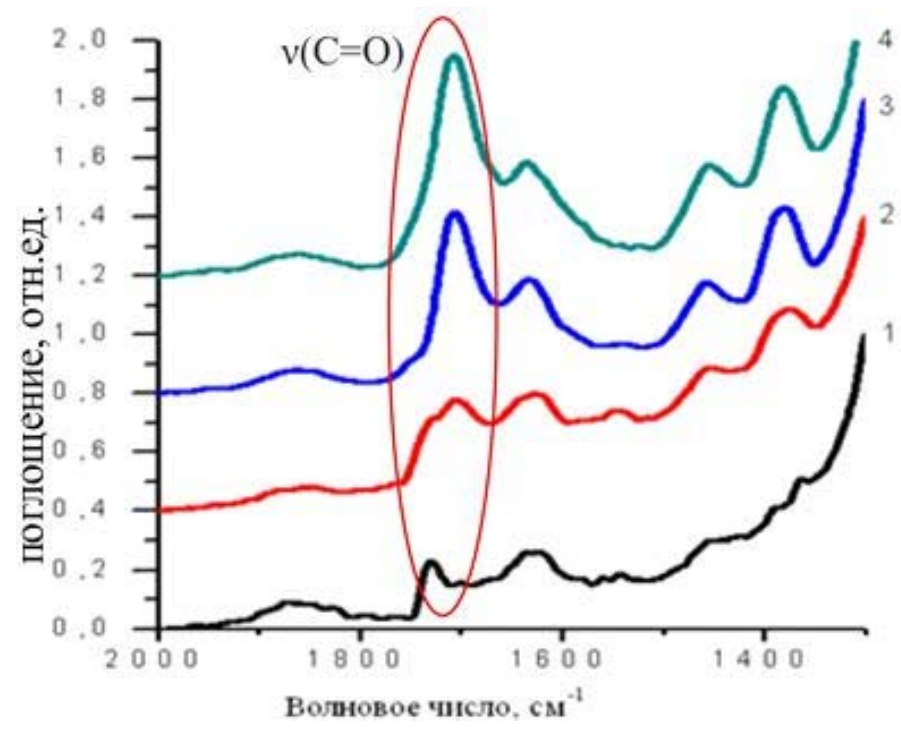

Рис. 4. ИК-спектры НПВО смесей ДАБ - аэросил: физическая смесь (1); смеси, механоактивированные в течение 5 мин (2); 15 мин (3); 30 мин (4) 


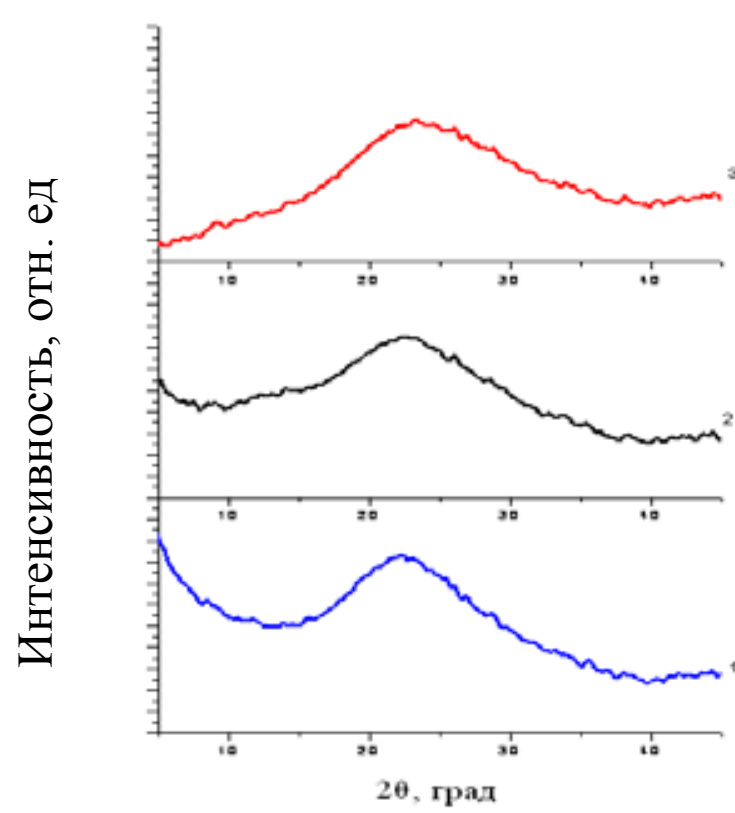

a)

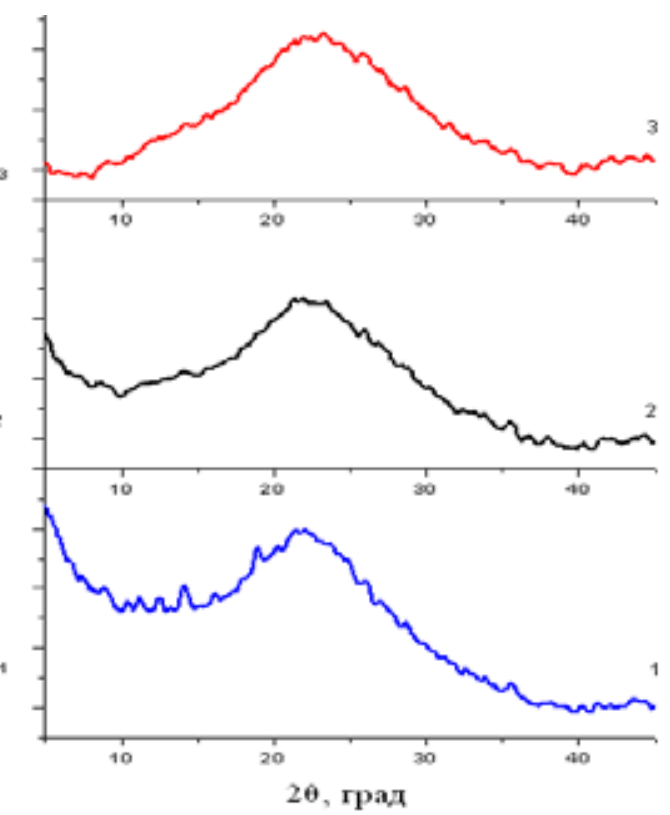

б)

Рис. 5. Дифрактограммы механоактивированных аэросила (а) и смеси ДАБ-аэросил (б) в течение: $1-5$ мин; $2-15$ мин; $3-30$ мин

что позволяет предположить увеличение длины связи в карбонильной группе в результате образования межмолекулярных водородных связей.

На рис. 5 представлены дифрактограммы механоактивированного аэросила (а) и механоактивированных смесей диацетата бетулина с аэросилом (б).

На дифрактограмме смеси диацетата бетулина с аэросилом, механоактивированной в течение 5 мин (кривая 1 на рис. 5 б), в области 10-20 градусов присутствуют рефлексы, свидетельствующие о наличии в смеси кристаллического диацетата бетулина. Некоторое уменьшение интенсивности рефлексов и их уширение на дифрактограммах смеси диацетат бетулинааэросил при увеличении продолжительности механической активации с 5 до 30 мин может говорить о диспергировании образцов. После 15 мин активации наблюдается почти полное исчезновение рефлексов диацетата бетулина в области 10-20 градусов, что свидетельствует о его аморфизации (дифрактограмма 2, рис. 5б).

\section{Композиты дипропионата бетулина с аэросилом}

Исходный ДПБ представляет собой кристаллы размером от 10 до 100 мкм (рис. 6а). В результате механической обработки кристаллы дипропионата бетулина измельчаются до размеров 5-10 мкм. Механическая обработка с полимерами приводит к тому, что дипропионат бетулина теряет кристаллическую форму. Смесь ДПБ с $\mathrm{SiO}_{2}$ является однородной и состоит из агрегатов частиц размером 5-30 мкм. После механической активации, как и в случае смесей аэросила с ДАБ, смесь гомогенизируется в результате диспергирования и перемешивания компонентов. 


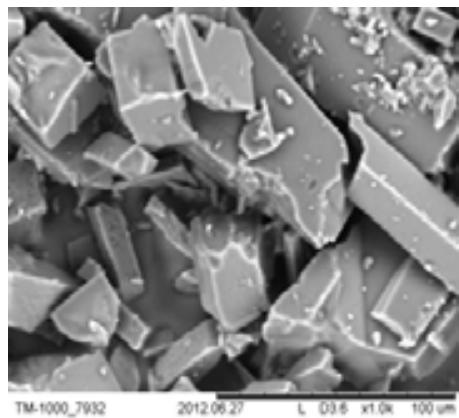

a

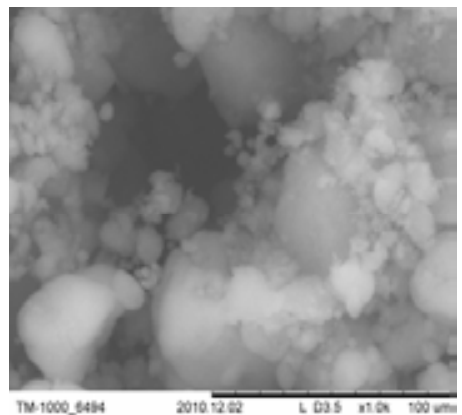

6

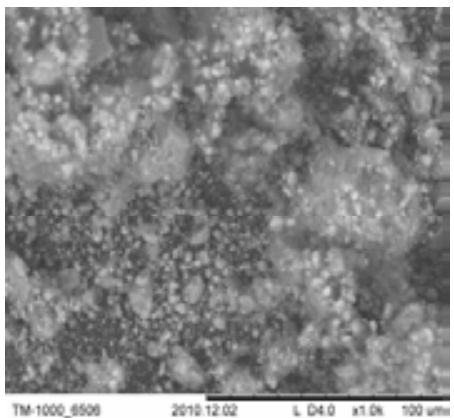

B

Рис. 6. Электронные микрофотографии (увеличение в 1000 раз): а - ДПБ, перекристаллизованный из этанола; б - аэросил; в - смесь ДПБ- $\mathrm{SiO}_{2}$, механоактивированная 15 мин

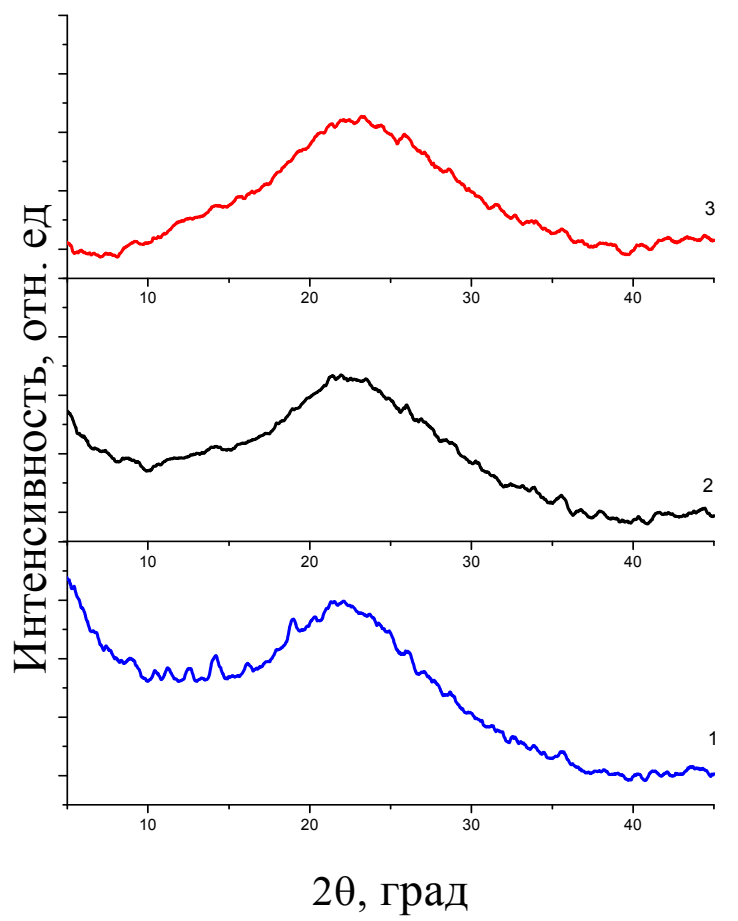

Рис. 7. Дифрактограмма смеси ДПБ-аэросил, механоактивированной в течение 5 (1), 15 (2) и 30 мин (3)

Методом ВЭЖХ подтверждено, что химический состав образцов дипропионата бетулина после механической активации не изменяется.

На рис. 7 представлена дифрактограмма смеси ДПБ с аэросилом после механической активации в течение 5-30 мин.

На дифрактограмме смеси ДПБ с аэросилом, механоактивированной в течение 5 мин, в области 10-20 градусов наблюдаются рефлексы, свидетельствующие о наличии в смеси кристаллического ДПБ. Уменьшение интенсивности рефлексов и их уширение на дифрактограмме 
смеси ДПБ с $\mathrm{SiO}_{2}$ при увеличении продолжительности механической активации с 5 до 30 мин может говорить о диспергировании образцов. После 15 мин активации на кривой 2 (рис. 7) наблюдается почти полное исчезновение рефлексов ДПБ в области 10-20 градусов, что свидетельствует об его аморфизации.

Таким образом, используемые физико-химические методы - электронная микроскопия, ИК-спектроскопия и РФА - показали, что механическая активация смесей диацетата и дипропионата бетулина с аэросилом приводит к образованию композитов, и диацилы бетулина в полученных композитах присутствуют в аморфном состоянии.

\section{Растворимость физических}

и механоактивированных смесей

С помощью ВЭЖХ была исследована концентрация ДПБ и ДАБ при растворении их смесей с аэросилом в воде.

Из данных, представленных на рис. 8, следует, что концентрация ДПБ в воде при растворении физической смеси ДПБ с $\mathrm{SiO}_{2}$ при продолжительности растворения 24 часа составила 0,7 мг/л. Растворимость ДПБ в воде возрастает после механической активации ДПБ с $\mathrm{SiO}_{2}$ в течение 15 мин и через 24 ч достигает 6,1 мг/л, что приблизительно в 8 раз больше растворимости физической смеси исходных веществ.

Концентрация ДАБ в воде при растворении физической смеси ДАБ с $\mathrm{SiO}_{2}$ составила 1,2 мг/л, а для механоактивированной в течение 15 мин смеси - 0,8 мг/л.

С увеличением продолжительности механической активации смесей ДАБ и ДПБ с аэросилом до 30 мин концентрация ДАБ и ДПБ в растворе не увеличивается, возможно, за счет укрупнения агрегатов диацилов бетулина с аэросилом, что может препятствовать переходу диацилов в раствор.

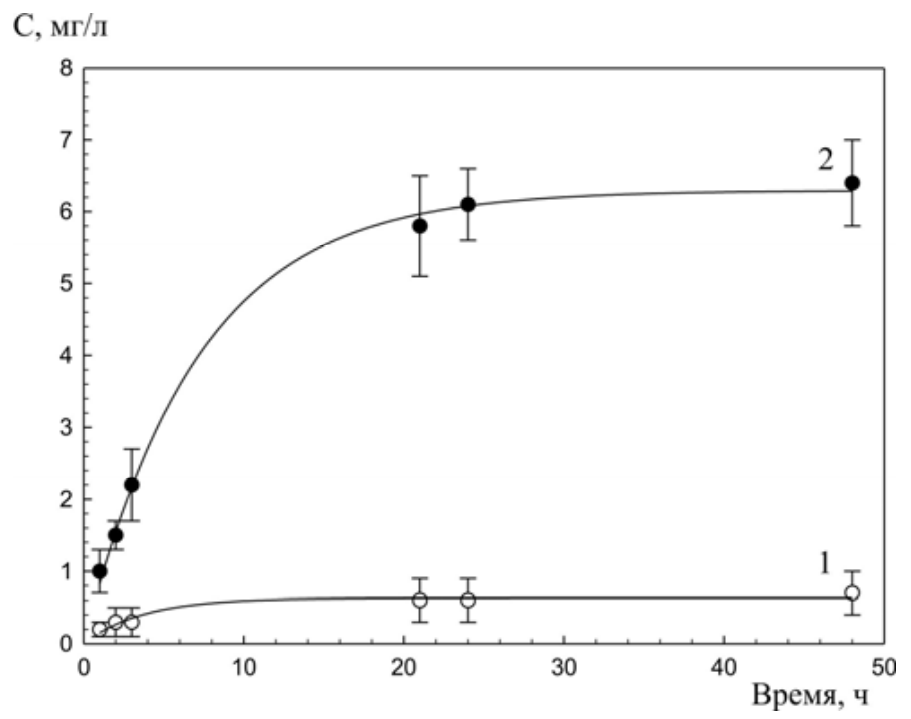

Рис. 8. Динамика изменения концентрации ДПБ в растворе при растворении: физической смеси ДПБ с аэросилом (1), механоактивированной смеси ДПБ с аэросилом (2) 
Увеличение растворимости диацилов бетулина в воде из механоактивированных композитов может быть связано с распределением ДАБ и ДПБ в аэросиле и их аморфизацией, что облегчает их последующее растворение.

\section{Выводы}

Получены механоактивированные композиты диацетата и дипропионата бетулина с аэросилом. С помощью физико-химических методов электронной микроскопии, ИК-спектроскопии и РФА показано, что механохимическая активация приводит к образованию композитов диацетата бетулина с аэросилом и аморфизации кристаллических диацилов.

Показано, что при растворении в воде физических смесей и механоактивированных композитов увеличивается раствормость диацилов бетулина в воде от 0,8 до 6,1 г/мл.

\section{Благодарности}

Работа выполнена при финансовой поддержке РФФИ (14-03-31900-мол_а).

\section{Список литературы}

1. Кузнецова С. А., Васильева Н. Ю., Калачева Г. С., Титова Н. М., Редькина Е. С., Скворцова Г. П. Получение диацетата бетулина из бересты коры березы и изучение его антиоксидантной активности // Журнал Сибирского федерального университета. Химия. 2008. Т. 1. №2. С. $151-165$.

2. Кузнецова С. А., Скворцова Г. П., Маляр Ю. Н., Соколенко В. А., Кузнецов Б. Н. Синтез дипропионата бетулина из бересты березы // Химия раст. сырья. 2011. №4. С. 77-82.

3. Кузнецова С. А., Кузнецов Б. Н., Скворцова Г. П., Васильева Н. Ю., Скурыдина Е. С., Калачева Г. С. Разработка способов получения диацилов бетулина из коры березы // Химия в интересах устойчивого развития. 2010. Т.18. С. 313-320.

4. Сымон А В., Веселова Н. Н, Каплун А. П, Власенкова Н. К, Федорова Г. А., Лютик А. И., Герасимова Г. К, Швец В. И. Синтез циклопропановых производных бетулиновой и бетулоновой кислот и их противоопухолевая активность // Биоорганическая химия. 2005. Т. 31, № 3. C. $320-325$.

5. Sugimoto M., Okagaki T., Narisawa S., Koida Y., Nakajima K. Improvement of dissolution characteristics and bioavailability of poorly water-soluble drugs by novel cogrinding method using water-soluble polymer. Int. J. Pharm. 1998. V.160. P. 11-19.

6. Liu R. (ed.) Water-Insoluble Drug Formulation. CRS Press. 2008. P. 669.

7. Shakhtshneider T.P., Boldyrev V.V. Mechanochemical synthesis and mechanical activation of drugs. "Reactivity of Molecular Solids". Ed. E. Boldyreva, V. Boldyrev. John Wiley \& Sons LTD. England. 1999. P. 271-312.

8. Шахтшнейдер Т.П., Кузнецова С.А., Михайленко М.А., Маляр Ю.Н., Болдырев В.В. Получение нетоксичных композитов бетулина с поливинилпирролидоном и полиэтиленгликолем // Журнал Сибирского федерального университета. Химия. 2012. Т.5, №1, C. $52-60$

9. Шахтшнейдер Т.П., Кузнецова С.А., Михайленко М.А., Маляр Ю.Н., Замай А.С., Болдырев В.В. Влияние механохимической обработки на физико-химические и противоопухоле- 
вые свойства смесей диацетата бетулина с арабиногалактаном // Химия природных соединений. 2013. №3. С. 401-404.

10. Кузнецова С.А., Маляр Ю.Н., Шахтшнейдер Т.П., Михайленко М.А., Дребущак В.А., Болдырев В.В. Механохимическое получение композитов эфиров бетулина с арабиногалактаном и изучение их физико-химических свойств // Химия в интересах устойчивого развития. 2013. T.21, № 6. C. 663-668.

11. Jonat S., Hasenzahl S., Drechsler M., Albers P., Wagner K.W., Schmidt P.C. Investigation of compacted hydrophilic and hydrophobic colloidal silicon dioxides as glidants for pharmaceutical excipients // Powder Technology. 2004. Vol. 141. No. 2. P. 31-43.

12. L.T. Zhuravlev. The surface chemistry of amorphous silica. Zhuravlev model // Colloids and Surfaces A: Physicochemical and Engineering Aspects. 2000. Vol. 173. No. 1-3. P. 1-38.

13. Gohel M. C. Improvement of nimesulide dissolution from solid dispersions containing croscarmellose sodium and Aerosil $200 / /$ Acta Pharmaceutica. 2002. Vol. 52. No. 4. P. 227-241.

14. Патент 2436791 РФ. Способ получения диацетата бетулинола / С.А. Кузнецова, Б.Н. Кузнецов, Г.П. Скворцова; Заявлено 06.05.2010; Опубл 20.12.2011. Бюл. № 35.6 с.

15. Патент 2469043 РФ. Способ получения дипропионата бетулинола/ С.А. Кузнецова, Г.П. Скворцова, Ю.Н. Маляр, Б.Н. Кузнецов; Заявлено 07.12.2011; Опубл. 10.12.2012. Бюл. № 34. 7с. 